\title{
Technical aspects of placing a second lumen-apposing metal stent at a separate session for a persistent walled-off pancreatic necrosis
}

A 35-year-old man, presented with a 12 $\mathrm{cm}$ walled-off pancreatic necrosis (WON) (>Fig. 1 a). A 15 mm lumen-apposing metal stent (LAMS, Hot AXIOS; Boston Scientific, Marlborough, Massachusetts, USA) was placed from the duodenal bulb ( Fig.2a). Computed tomography (CT) imaging 3 days later showed that the stent was in place ( Fig.1 b). A subsequent necrosectomy was performed, resulting in improved symptoms.

The patient returned with recurrent symptoms. CT imaging showed that the collection around the neck of the pancreas had improved; however, the collec-

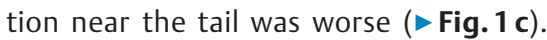
On endoscopy, the scope could not reach the tail through the stent because of the narrow tract from the neck of the pancreas to the tail ( $\vee$ Video $\mathbf{1}$ ). The decision was made to place a second $15 \mathrm{~mm}$ LAMS in a transgastric fashion to drain the component of the WON in the tail of the pancreas. This was technically challenging because the initial LAMS had drained the fluid from the collection, leaving solid debris within the cavity. Therefore, under endoscopic ultrasound (EUS) guidance, a 19 gauge needle was used to inject $100 \mathrm{~mL}$ of sterile saline transgastrically into the cavity to assist the stent delivery. The second LAMS was placed under EUS and endoscopic gui-

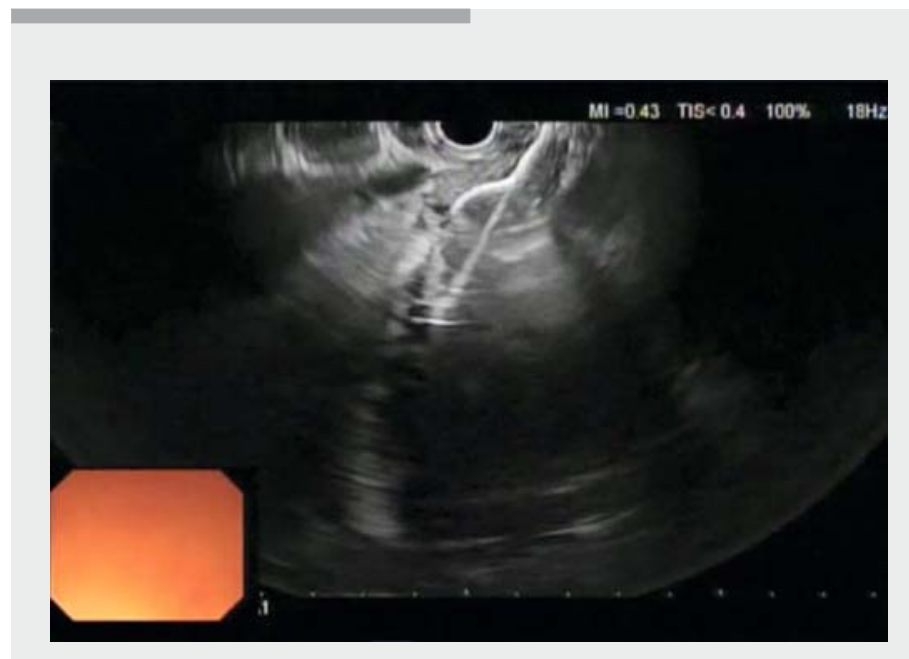

Video 1 Video demonstrating the placement of two lumen-apposing metal stents at different sessions to drain a walled-off pancreatic necrosis.

dance using an enhanced electrocautery system (Hot AXIOS) (> Fig.2b). More force was needed to push the stent delivery device into the cavity than the force used for placement of the first LAMS because of the solid debris. Follow-up CT imaging showed that both LAMS were in place ( $\triangleright$ Fig.1d). A subsequent necrosectomy was performed 3 days later through the second stent and the first stent was removed ( $\nabla$ Video $\mathbf{1}$ ).

At 4 weeks after placement of the second stent, the patient was asymptomat- ic. Follow-up CT showed resolution of the WON (• Fig. 1 e).

This report demonstrates that placement of a second LAMS during a different session is feasible in WON. Endoscopic ultrasound-guided saline injection and use of the electrocautery-enhanced deliver system are useful maneuvers.

Endoscopy_UCTN_Code_TTT_1AS_2AD 

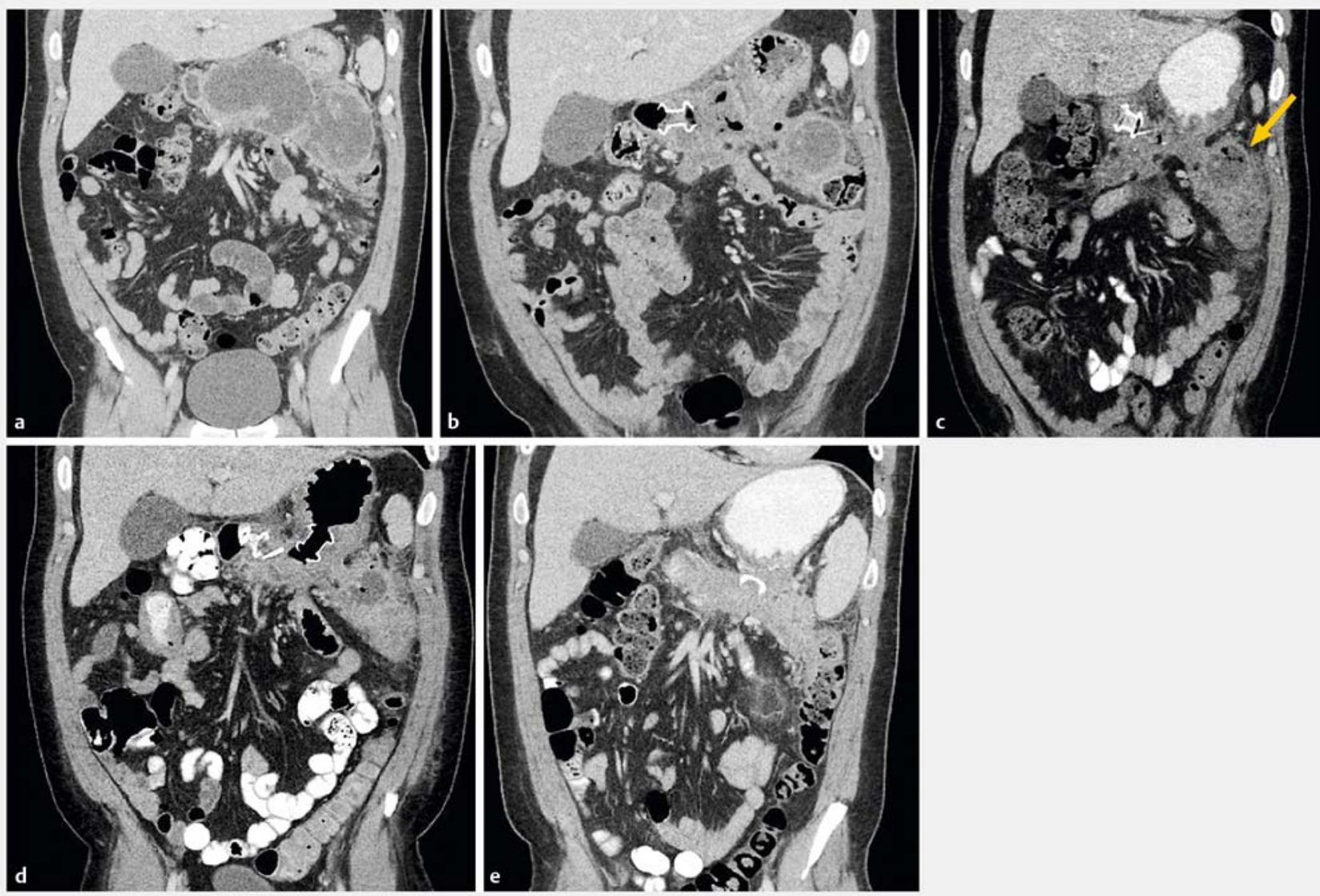

- Fig. 1 Computed tomography (CT) of the walled-off pancreatic necrosis (WON) and its treatment course. a The WON at presentation. b The WON 3 days after placement of the first lumen-apposing metal stent (LAMS). c The WON 10 days after placement of the first LAMS, showing the worsening collection in the tail of the pancreas. $\mathbf{d}$ CT after placement of the second LAMS transgastrically. e The WON 4 weeks after necrosectomy through the second stent. Note, the first stent was removed during the second necrosectomy session.
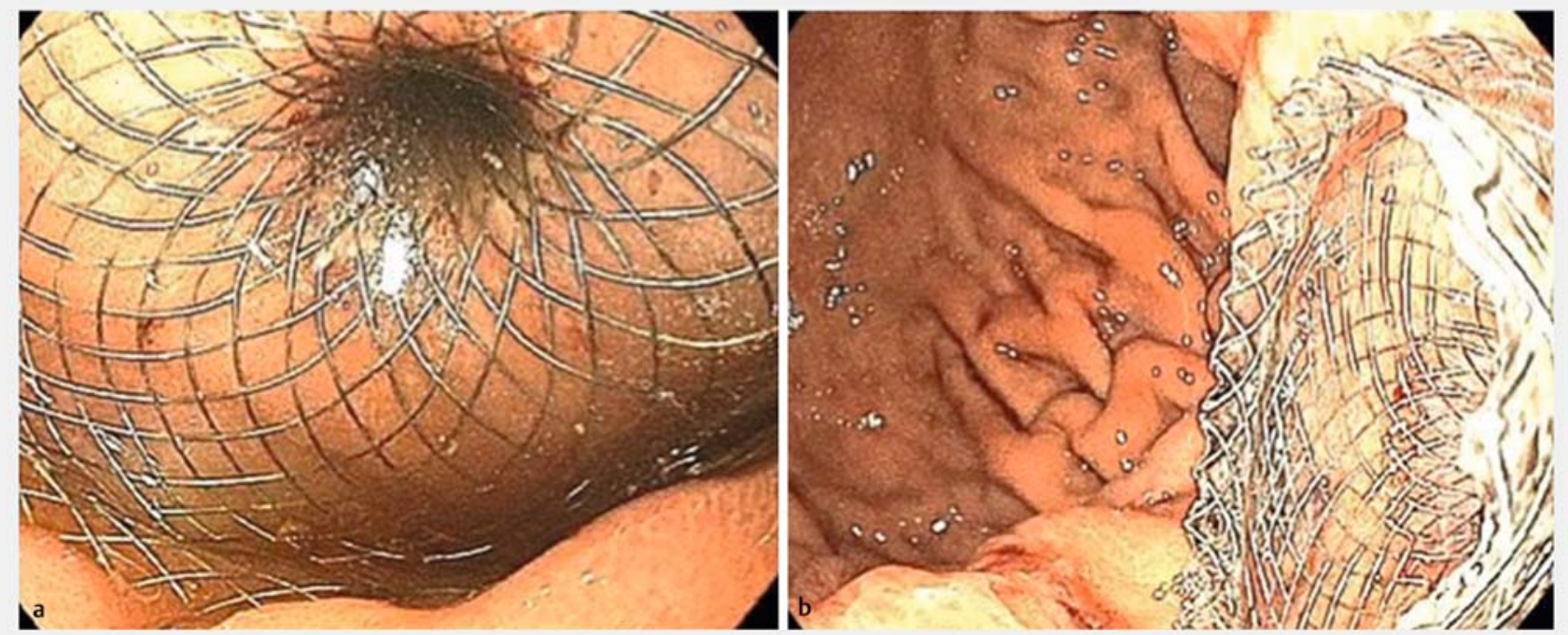

Fig. 2 Lumen-apposing metal stent (LAMS) placement. a The first LAMS was placed in the duodenal bulb. $\mathbf{b}$ The second LAMS was placed in the stomach. 
None

The Authors

Arvind J. Trindade, Yun Kim, Brian Markowitz, Petros C. Benias

Division of Gastroenterology, Hofstra Northwell School of Medicine, Long Island Jewish Medical Center, Northwell Health System, New Hyde Park, New York, United States
Corresponding author

Arvind J. Trindade, MD

Long Island Jewish Medical Center, Division of Gastroenterology, 270-05 76th AVE, New Hyde Park, NY 11040, United States Fax: +1-718-470-5509

arvind.trindade@gmail.com

\section{Bibliography}

DOI https://doi.org/10.1055/s-0043-108541

Published online: 14.6.2017

Endoscopy 2017; 49: E190-E192

(c) Georg Thieme Verlag KG

Stuttgart · New York

ISSN 0013-726X
ENDOSCOPY E-VIDEOS

https://eref.thieme.de/e-videos

回回 Endoscopy E-Videos is a free access online section, reporting 口if: on interesting cases and new techniques in gastroenterological endoscopy. All papers include a high quality video and all contributions are freely accessible online.

This section has its own submission website at

https://mc.manuscriptcentral.com/e-videos 